\title{
Decarbonizing warehousing activities through digitalization and automatization with WMS integration for sustainability supporting operations
}

\author{
Daria Minashkina ${ }^{1}$, and Ari Happonen ${ }^{1 *}$ \\ ${ }^{1}$ LUT University, School of Engineering Science, 53850 Lappeenranta, Finland
}

\begin{abstract}
The current strong outsourcing trend dictates that the efficiency of outsourced warehousing is a big contributing impact factor for the carbon footprint from supply chains. A good warehouse management system boosts warehousing eco-friendliest by reducing space waste and unnecessary number of material movements, to ensure continuous fast materials flow and to keep the heating and cooling costs to a minimum. All this may happen on some lengths inside the traditional manual warehousing scenes, but in fact, if the highest level of efficiency is wanted/needed, the operator shall need to automate, digitalize and robotize their operations. Authors presents an example of automation in the warehousing context, where the warehouse operator is capable of turning around an order line as an outgoing packet, even in high peak load times under $3 \mathrm{~h}$ time period. This sort of efficiency means less needed storage space as items stay less time in the warehouse and such automatization also gives the 3PLs possibility to store materials in high rising automated systems like automated storage and retrieval systems to optimize their space usage. All combined, the future warehouse operations can make a positive impact on efforts to reduce overall $\mathrm{CO}_{2}$ emissions made by supply chains.
\end{abstract}

\section{Introduction}

This publication is based on data analysis done for authors' WMS related systematic literature review [1] (SLR later on) work about a revealed knowledge gap in the literature regarding 3PLs (third-party logistics) using warehouse management system (WMS hereinafter), which is proceeded now in the process follow up publications. These publications do a comprehensive deep analysis of the studied SLR materials. The step by step article analysis is indicating that WMS and 3PL practical operations are not so much well studied, especially, in the technical side of WMSs supporting automated equipment and warehouse operations in the 3PL and WMS context. These two new academic publications are a continuation for work that has started already in 2017 [2], and they focus on deep analysis and SLR work on WMS and 3PLs topics.

First of all, as the efficiency of outsourced warehousing is a big contributing impact factor for the carbon footprint from supply chains [3, 4], it is interesting that so little is known / written about the value of WMS for decarbonization of warehouse activities. At the same time, there is well known constantly growing concern about sustainable business and searching for more energy-efficient new ways for operations/actions to save energy, decrease $\mathrm{CO}_{2}$ emissions and minimalize industrial waste [5]. The trend itself is just as important for industrialized countries as it is for developing countries too. However, industrialized countries should become trailblazers with all the technology options and possibilities available for them, and by doing so give the lead for the rest of the World.

Minimizing carbon footprint in terms of decarbonizing warehousing activities has not gained as much attention compared to reducing $\mathrm{CO}_{2}$ during manufacturing/production, transportation, and recycling. Nevertheless, warehousing does have its own impact like any other parts of any product generating chain (buildings, inside warehouse logistics, resources usage and so on) and it also consumes energy too [6]. Negative warehouses' environmental impact is generated by energy consumption and produced emissions for lighting, heating, cooling, air conditioning and material handling [7]. Logistic buildings account for approximately $10 \%$ (300 $\mathrm{CO}_{2}$ mega-tonnes) of logistic and transport sector activity (2,800 $\mathrm{CO}_{2}$ mega-tonnes) which is, in turn, 5,5\% of total $\mathrm{CO}_{2}$ emissions [8].

As it is the most common for 3PLs to be the operators to implement the practicalities for outsourcing of warehousing operations $[9,10]$, they could take more responsibility for making warehousing more sustainable. Moreover, this can be required by a company that sings an outsourcing contract. Conversely, there are studies regarding barriers preventing companies to decarbonise their warehousing operations such as a lack of

\footnotetext{
${ }^{*}$ Corresponding author: ari.happonen@lut.fi
} 
government incentives to encourage sustainable warehouse operations, a lack of sustainable technologies on market, reluctant suppliers to collaborate in sustainability, unwilling and not concerned customers about sustainability [11].

With the help of automation and digital technologies, implemented into and installed in daily use, the sustainability efficiency enhancement opportunities have become truly possible. Meanwhile, logistics service providers do seem to be more engaged into proceeding with incremental improvements (adopting existing technologies improvement) rather than on jumping into radical technologies / new innovative ideological concepts [12] (and generating completely new technologies) [13]. With this background, this publication focuses on the WMS and automated technologies [14] adopted by 3PLs to facilitate warehousing operations and reduce environmental effects through further optimization. In other words, authors specially discuss practical ways, how a 3PL could add efficiency into their operations to drive down $\mathrm{CO}_{2}$ emissions with digitalization, automatization and robotization or e.g. with solar panels on warehouse roof, which is a way for 3PL to locally produce some of the energy they need to run their operations, to charge their warehouse vehicles and keep up air conditioning running among other equipment).

With this literature and practical field study experience data and experience-based knowledge in hands provided in this publication, new 3PLs should have more to lean on taking steps into more sustainable working models directions. For more seasoned 3PLs, this publication is designed to give opportunities to revise their knowledge base against the presented newest research materials. In addition, as it is mentioned earlier, this publication aims to show how the environmental impacts of industrialized warehouse operations can be mitigated.

\section{Background and research focus}

This paper examines the technical side of modern warehouses in relation to WMS. As it is already discussed earlier, we value that WMS adds to warehouse activities decarbonisation. WMS is a specialized software platform designed to automate and optimize the functions of a warehouse like acceptance and placement of materials, slotting tailoring, processing and completing orders with an allowance for prioritization, shipping, inventory adjustment and so on. WMS can provide all information about processes, controlled them and optimize, like modelling inventory demand based on historical data predicting future optimization needs [15]. In short, WMS is the brain of efficient warehousing [16]. WMS is an essential attribute of "best-in-class sustainable warehouse" [17]. So, speaking about decarbonising of warehouse activities we cannot not to mention the definition of sustainable warehouse. Decarbonizing warehouse activities belongs to sustainable warehouse definition what means "a set of organizational and technological solutions aimed at efficient realization of the warehouse process.... maintaining the highest social standards, minimizing the environmental impact with regard to financial efficiency" [18]. Briefly, sustainable warehousing should positively affect all 3 pillars of sustainability: environmental, social and economic [19, 20]. Sustainable warehouse management and characteristic belonging to sustainable warehousing are studied by researches, but not the role of WMS and automated systems in relation to sustainability environmental issues [21]. On the other hand, a multitude of publications, related to sustainable warehouse options for heating, lighting, water and energy consumption and waste management are easy to be found [22]. Even though the mentioned example publication does address a subject of sustainable warehousing, it does not deal with sustainable friendly materials in building structure itself or discuss any building assessment systems, neither the paper is about social or economic aspects of warehousing.

This publication mostly limits out the actions 3PLs could do e.g. with their customers on the warehouse optimization collaboration side to improve the efficiency with customer data, as any sort of big focus area for this study. For that sort of publications, the reader is referred to read e.g. the following publications [23-26]. In this publication, authors have set a goal to highlight the value of technological solutions deployed in warehouses, which not only increase warehousing efficiency, but also positively influence on the environment in terms of both for nature and people. In other words, authors present the literature related to the topic area and provide practical case examples based on previous practical case studies and privileged research visits to automated warehouses in Finland.

\subsection{Sustainable warehousing with WMS and digitalization}

The optimisation is in the heart of WMS, which gives this software-based solution its ability to bring sustainability in warehouses. In the following, we present literature about already known WMS functions which not only bring operations costs \& time reduction for warehousing operations, but also optimise warehousing activities positively influencing our environment producing less $\mathrm{CO}_{2}$ emissions. WMS is mentioned in the intrinsic principles to supply chain digitalization as the one which can guarantee flow and visibility control providing real-time transparency and velocity [27]. If it is needed, additional technologies like RFID tagging etc. can always be used with extremely high valued items [28] / environmentally hazardous products, but in principle, any good WMS should provide good products, items, and processes trackability already in normal implementations levels.

The crucial role of WMS is to guarantee sustainable performance and advise to get maximum usage of storage area, in addition, packaging waste could be avoided by using reusable containers and increase usage of energy-efficient handling technologies [29]. For 
example, correctly configured and managed WMS helps to allocate the best places for inbound materials to be stored and to be picked later, regroup and reclassify inventory to guarantee goods outcoming velocity [30, 31]. If this system is advanced enough, it could also support demand and supply synchronisation for specialised industry areas, e.g. like a module for machinery industry supply chains [32]. These sorts of multiple different optimization algorithms can, in turn, results in lots of monetary savings and resource savings. Moreover, the cross-docking function of WMS for incoming goods helps to skip unnecessary storage operations, just by sending these items directly to output points for further pick up [33], to avoid unnecessarily use of the limited warehouse resources.

For instance, WMS can generate algorithms and rules to perform warehouse tasks such as goods allocations, route picking lists, orders division [34]. The module of routes policy assisting a picker is usually absented in standard WMS but belongs to advanced customized WMS [35] as it does the more dynamic inventory SKU (stock keeping unit) amounts balancing models [36] Nevertheless, even just with the help of WMS route optimisation function, a warehouse operator having a picking list with a number of goods in mixed locations order on hands does not need to waste time deciding in what sequence to assemble order relying on own knowledge about SKUs location [4] and in case of using a forklift a vehicle does not need to waste energy for unnecessary additional driving. Additionally, since WMS supports traditionally tasks interleaving (various tasks happening in one place are combined to maximize productivity), a warehouse worker can do several tasks on the road e.g. to prepare goods for the next pick in a single route [33]. The research of [37] has nicely demonstrated this logic of inner warehouse operations task interleaving by travel distance reduction of a forklift involved into multi-picking tasks $(60.7 \%)$, single case picking and inventory replenishment at the same time $(50.3 \%)$, put-away + replenishment + full pallets picking $(40.7 \%)$. And for people, the labour management module in WMS can help to optimize warehouse work capacity and personnel loads [38]. All this will, in turn, improve the forklift operations performance, and save energy too by reducing any extra travelling times related to more traditional routing algorithms.

Another WMS advantage associated with digitalization is that paperless storing allows online and on time data exchange between a warehouse worker and a WMS application saves our environment resources by minimizing paper waste too [39, 40]. For instance, paper picking list can be damaged/torn up or become wet/dirty and so on while ICT (information and communication technology) devices like RFID tags [41, 42], can prevent this.

For technology enhancing picking, the most wellknown picking supporting systems used in a warehouse are light-directed systems such as pick-to-light and putto-light, pick-to-voice, virtual display-directed picking systems. And considering the paper waste, statistically speaking approximately $100 \mathrm{~kg}$ of land is wasted for every ton of paper used [43]. Used paper can easily end up in the landfill, after maybe one or two usage rounds, which is a waste, compared to "digital paper" used in ICT equipment, with the same end-use purpose. According to statistics, reading 8 pages document from a laptop computer generates 2-times less $\mathrm{CO}_{2}$ (13.8 g) compared to the same printed document on two-sided paper print (30.3 g) [43]. Another example comes from the study about office paper consumption where the selected higher education institutions used 13 tons of A4 size paper per year which were made by cutting 312 trees, 33,6 tons of $\mathrm{CO}_{2}$ emissions, around $145 \mathrm{MWh}$ of energy consumption, approximately 13,4 tons of solid wastes and $940 \mathrm{~m}^{3}$ of water used [44]. Moreover, from the digitalization point of view, even WMS could be sort of the next level digitalized by offering it as a cloud service, which should be a bit more sustainable way of using the system, than one which is installed as a standalone solution in a site [45].

With the help of WMS, it is possible to set and monitor key performance indicators (KPIs) of warehouse activities measurements such as work performance, warehouse productivity, order fulfilment, inventory management data, workforce data and etc., which then can be used on various levels of a company to measure not only warehouse financial performance, but also the sustainable performance metrics too [17]. Sustainability and circularity dashboards can visualise warehouse KPIs, like in the study [46], where Sustainable Warehouse Management prototype is provided with a separate section of Environmental Indicators visualization to indicate how many trees would be needed to be planted to compensate $\mathrm{CO}_{2}$ emission generated by warehousing operations.

\subsection{Practical case example of Finnish automated and digital warehouses}

As examples, authors present here practically witnessed cases about sustainable highly efficient warehouse concepts with additions of public information released from the cases. Especially, some examples from high technology equipped warehouses, which should be excellent examples for others to demonstrate technologybased options for warehouse decarbonisation.

\subsection{Automated warehouse case Hakkila}

Warehousing performance can be boosted with the help of automation. For example, in the case study report for the 3PL [14] authors consider the WMS integrations and deployment of the Automated Storage Retrieval System (AS/RS thereafter) having 400000 storage places and operated by 46 shuttle robots in $20000 \mathrm{~m} 2$ warehouse [47], its operation bottleneck scenarios and possible ways of increasing efficiency. Most of the warehousing related activities are done by the AS/RS (only goods receiving, inspecting and their recording to the system are done by humans), also picking is done in 2 automated picking stations where the AS/RS sends all needed products, moving of all products inside the warehouse is done in totes on conveyor belts, packing in 
5 stations is also done by human. The system is so automated, that warehouse personnel do not need to travel inside the warehouse for manual order picking as all items, which are stored into the large-scale automated warehouse unit, are conveyer transferred conveniently directly for the workers. AS/RS sends already picked orders altogether to packing stations where people wait for the picked deliveries to be packet on outgoing shipment containers/packets/ballets etc., whatever is needed by the shipment. The advantages Hub Logistics offers to its customers with such automated and digitalized warehouse are process quality with high accuracy and security levels equal to almost 100\%, operation speed and operational reliability with constant performance measurement and reporting. Hakkila automated warehouse needs only 3 hours to complete a customer order to delivery, has picking speed of 3500 rows per day, while in an average manual warehouse order completion time would be 12 hours and picking speed would be 250 rows per day [47]. The definite advantage of this system is that it can work during the night-time (requiring no lighting or air conditioning like humans would need to move inventory totes around) relocating inventory according to later orders fulfilment and facilitate work productivity. This particular logistics operator has been one of the forerunners in Finnish demand-supply chain synchronisation activities [32] in past year and now, deploying this novel AS/RS based service is a clear example of how the travelling time of people in a warehouse and usage of e.g. vehicles can be reduced by $\mathrm{AS} / \mathrm{RS}$ working 24/7, to take a new step on shortening the cycle times in warehousing, once again boosting the possibilities to synchronize demand and supply, which reduces logistics waste. Additionally, whole warehouses energy consumption related sustainability was re-enhanced on 9.1.2019 when new solar panel solutions was booted up with 560 panels. The solar panel system provides around $125 \mathrm{MWh}$ per year for the warehouse, which is $10-20 \%$ from the warehouses yearly consumption, depending on Finnish weather conditions per year and how close to the maximum capacity the warehouse will be on any given time.

\subsection{Finnair Cargo Cool Terminal}

Finnair Cargo Cool Terminal in Helsinki Airport opened in 2018 and it is in fact acknowledged to be one of 7 most modern air cargo terminals in the world [48]. This is a $31,000 \mathrm{~m}^{2}$ air cargo terminal which accumulates the latest robotics technologies and intelligent warehouse automation [49]. The advanced terminal, equipped with state-of-the-art temperature-controlled storage spaces and technologies with separate dedicated storage areas for seafood, pharma medicines and other cargo [50, 51]. The cold storage Finnair Cool Cargo Terminal works in the principle like cold storage centres do pallet-in and pallet-out operation to guarantee the accurate and timely supply of perishable items [52]. Totally it takes just 36 hours for a Norwegian salmon to be in Japan [53]. Also, the fact that perishable items are sent to departure only
30 minutes before the actual one, unlike all general cargo go 50 minutes before what saves time [50]. Shorter the perishable goods are "inside" the supply chain, more sustainable it will be, because less and less energy is needed to keep the salmon cold. In temperaturecontrolled areas, the perishable cargo and seafood are kept with the temperatures between $6^{\circ}$ and $8^{\circ} \mathrm{C}$, while the pharmaceutical area temperature is $20^{\circ} \mathrm{C}$ with the storage temperature between $2^{\circ}$ and $8^{\circ} \mathrm{C}$ for frozen goods [50]. Finnair Cool Terminal carried daily 700 tons of cargo [54]. This cargo terminal is built according to the Building Research Establishment Environmental Assessment Method (BREEAM) environmental standards with green cargo design where there are 1,200 solar panels installed on the roof providing the building with $10 \%$ of its energy needs. At the same time, the highly automated storage area for 580 ULD (Unit Load Device) is used to [54] and AS/RS saves energy, as it does not require lots of lighting to perform its tasks [55] [56].

Then with the help of the automated guided system, each forklift is sent to its nearest location task reducing driving time and saving driving energy [56]. Finnair Cool hub is a fine example of an automated paperless digital future warehouse improving air freight efficiency [51].

\section{Discussion and managerial applications}

This paper sheds the light on the issues of 3PLs using WMSs and automation in conducting warehouse activities. With this paper, authors intend to show how 3PLs using WMS is not just a tool to bring efficiency to warehouse processes, but it also adds value to decarbonization of warehouse operations. As the paper shows, new technologies do not often bring only cost, time and resources savings, but sustainability gains too. Mentioned case examples introduce sustainable warehousing practices which lead to better business performance like faster order picking speed, shorter personnel travelling time in a warehouse, higher warehouse productiveness and operations efficiency. With new technologies, a 3PL can do more warehousing using fewer resources and less space. Moreover, there are certain benefits yielded for 3PLs following such an approach. In case if a 3PL operator promotes own more sustainable operations, it has a certain competitive advantage along others on market, because such activities can attract new clients into this sustainable aware 3PLs direction. Using renewable energy (e.g. installing solar panels, improving insulation and supporting windmills) can open up new reliable access to in-house energy sources, and also reduce energy supply shortage and price volatilities. This, in turn, gives the 3PL possibility to be more independent from market energy prices and most likely gives them advantages against new governmental sustainable policies and raised waste taxes.

Given the fact how little these WMS have been studied in sustainability context and on other hand how 
unlikely focus area logistics centres seem to be for university RDI collaboration work with the Universities, authors would like to suggest following. Based on previous highly productive collaboration activities within university - company cross section with hackathon like approaches $[57,58]$ using these to challenge WMS function development for sustainability direction seems a great possibility for both the WMS developers and for the 3PL operators and their customers too. Especially when considering some of the academic findings, related on sustainability enhancing hackathons [59].

\section{Conclusion and future study suggestions}

This publication discusses warehousing logistics carbon footprint reduction opportunities presented with digitalization and with WMS usage cases. With proper system implementations, 3PLs can see $\mathrm{CO}_{2}$ reduction generated by their operations if they embrace the digitalization, automatization and robotization options available for them. And by embracing the data collection, networking and close collaboration with their customers, they could also start to steer their whole customer network towards more carbon neutral activities direction, if they start to view their customer pool as a fleet of customer [60] and making more decisions for the network [61], instead of just considering clients as separate business cases.

In the future, it would be interesting to examine in detail the specific numbers WMS adds to the efficiency in warehouse decarbonizing. Specially the effect of WMS for both the logistics operator and their customers as total emission reduction activity provider and ways digitalization could transformation logistics operators into sustainability knowledge providers [62] in tangible products supply chains. And other hand, if the product related data, like transportation damages and materials used in product, would be collected from the supply chains, AI and ML could be used efficiently in future to enhance product design to take these challenges into account to minimize product design \& transportation damages related resource wastes [63]. Also, benchmarking and comparing various WMS against possibilities to reduce the environmental negative impact would be useful, both in the academic and in a practical sense. For the governmental side of things, added knowledge of automated systems and digitalized operations $\mathrm{CO}_{2}$ reduction possibilities might bring up new ideas for fair but result in productive regulations to change large parts of supply chains into more sustainable directions. Additionally, 3PLs should not try to do all the work themselves, but they should e.g. find ways to formalize their networking capabilities [64] and collaborative sustainability development activities. Also, as found in literature studies review, it is highly suggested to add more publications about WMS and their effects to sustainability and what 3PLs should ask when planning to implement these systems from WMS providers from the sustainable point of view. Specially, could WMS and 3PLs help companies to manage their assets on stocks in whole fleet level and make it less resource wasting, as currently assets are not handled too efficiently in fleet level [65].

\section{References}

1. D. Minashkina, A. Happonen, International Journal of Supply Chain and Inventory Management, Systematic literature review and research gap issues on 3rd party logistics operator selecting WMS for efficient operations for customers, 19 (2019)

2. D. Minashkina, Master's thesis (LUT), Development of the framework for the 3PL company for selecting WMS based on customers' operational characteristics (2017)

3. B. Sundarakani, M. Goh, R. de Souza, C. Shun, ISL2008, Measuring carbon footprints across the supply chain (2008)

4. C. Das, S. Jharkharia, J. Manuf. Technol. Manag. Low carbon supply chain: a state-of-the-art literature review (2018)

5. M. Kückelhaus, Deutsche Post AG, How the digital revolution is changing logistics: insights from our 2018/19 Logistics Trend Radar, https://deliveringtomorrow.com/how-the-digital-revolution-ischanging-logistics-insights-from-our-2018-19logistics-trend-radar/ (2018)

6. J. Freis, P. Vohlidka, W. Günthner, Sustainability, Low-carbon warehousing: Examining impacts of building and intra-logistics design options on energy demand and the CO2 emissions of logistics centers., 8, 5, 448 (2016)

7. J.M. Ries, E.H. Grosse, J. Fichtinger, IJPR, Environmental impact of warehousing: a scenario analysis for the United States, 55, 21, 6485-6499 (2017)

8. S. Doherty, S. Hoyle, World Economic Forum. Supply chain decarbonization: role of transport and logistics in reducing supply chain carbon emissions, http:/www3.weforum.org/docs/WEF LT SupplyC hainDecarbonization_Report_2009.pdf (2009)

9. E. Salmela, A. Happonen, ISL 2009, Role of Logistics Service Provider in Supply Chain Between Manufacturer and Subcontractor (2009)

10. A. Happonen, E. Salmela, ISL 2011, The Change of the Logistics Service Provider's Decision Making Role in Machinery Industry - from Resource Provider to Strategic Partner, 836-844 (2011)

11. S. Goh, IJPDLM, Barriers to low-carbon warehousing and the link to carbon abatement, 49, 6, 679-704. (2019)

12. E. Salmela, A. Happonen, J. Huiskonen, IJMR, New Concepts for Demand-Supply Chain Synchronization, 7, 2, 148-164 (2012)

13. M. Mathauer, E. Hofmann, IJPDLM, Technology adoption by logistics service providers (2019) 
14. D. Minashkina, A. Happonen, LUT Research Reports series report, Operations automatization and digitalization - a research and innovation collaboration in physical warehousing, AS/RS and 3PL logistics context, 86, ISSN 2243-3376, 66 (2018)

15. A. Happonen, PICMET 2012, Adjusting Inventories Based on Demand Prediction Using Dynamic Inventory Balancing Model, (2012)

16. B. Barik, Medium, Driving Digital Transformation with a Smarter, Connected WMS, https://medium.com/@,biplob.barik/driving-digitaltransformation-with-a-smarter-connected-wmsb184f871dc27 (2018)

17. T. W. Amjed, N. J. Harrison, ADSPI 2019, A Model for sustainable warehousing: from theory to best practices, 1-28 (2013)

18. M. Malinowska, A. Rzeczycki, M. Sowa, SHS Web of Conferences, Roadmap to sustainable warehouse, 57, 01028 (2018)

19. W.H. Clune, A.J. Zehnder, JEP, The Three Pillars of Sustainability Framework: Approaches for Laws and Governance., 9, 3, 211 (2018)

20. B. Purvis, Y. Mao, D. Robinson, Sustainability Science, Three pillars of sustainability: in search of conceptual origins (2018)

21. K. Azadeh, R. de Koster, D. Roy, Robotized warehouse systems: Developments and research opportunities, SSRN Electronic Journal, (2017)

22. S. Mulder, Master's thesis, University of Twente, Sustainable warehousing; An empirical research at Unilever on building options and collaboration models in sustainable warehousing (2013)

23. E. Salmela, A. Happonen, J. Huiskonen, IJCENT, Best Collaboration Practices in Supply Chain of Technical Wholesale Items, 2, 1, 16-38. (2011)

24. J. Rantala, A. Happonen, ISL 2012, Success factors of collaborative product development in production networks, - New Horizons in Logistics and Supply Chain Management, 120-127 (2012)

25. A. Happonen, E. Salmela, SMART 2011 Research Forum, Scheme for Inventory Management Parameter Readjusting Based on Demand Anticipation Process, 12 (2011)

26. E. Salmela, A. Happonen, EurOMA Conference, Synchronization of Demand and Supply in a Supply Chain Manufacturing Industrial Products, 9 (2009)

27. R. Handfield, Logistics, Preparing for the era of the digitally transparent supply chain: a call to research in a new kind of journal, 1, 2, p. 15 (2017)

28. H. Hämäläinen, E. Salmela, A. Happonen, ISL 2007, RFID on Item Level Tagging in Supply Chain with High-Valued Products (2007)

29. R. Dubey, A. Gunasekaran, T. Papadopoulos, S. J. Childe, K. T. Shibin, S. F. Wamba, J. Clean. Prod., Sustainable supply chain management: framework and further research directions, 142, 1119-1130 (2017)
30. H. Min, Int. J. of Logistics Research and Applications, The applications of warehouse management systems: An exploratory study, 9, 2, 111-126 (2006)

31. R. Manzini, (Ed.) Springer, Warehousing in the global supply chain (2011)

32. A-M. Hietajärvi, E. Salmela, A. Happonen, J. Hemilä, LRN, Demand-supply Chain Synchronisation in the Finnish Machinery Industry, 8 (2009)

33. D. Piasecki, World Trade, Warehouse Management Systems 17, 60-69 (2004)

34. P. Zajac, Springer International Publishing, Evaluation method of energy consumption in logistic warehouse systems (2015)

35. K. J. Roodbergen, I. F. Vis, Jr. G. D. Taylor, IJPR, Simultaneous determination of warehouse layout and control policies, 53, 11, 3306-3326 (2015)

36. A. Happonen, E. Salmela, PICMET 2011, Dynamic Inventory Management Parameters Adjusting Scheme as a Logistics Service (2011)

37. A. Burinskiene, A. Lorenc, T. Lerher, IJSIMM, $A$ simulation study for the sustainability and reduction of waste in warehouse logistics, 17, 3 (2018)

38. Ehrhardt Partner Group, Making the Case for Driving Digital Transformation with a Smarter, Connected WMS, https://scg-

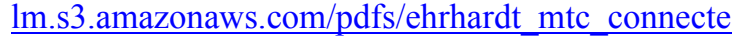
d wms 100118.pdf (2018)

39. N. Faber, M. B. M. de Koster, A. Smidts Organizing warehouse management, J. Oper. Prod. Manag., 33, 9, 1230-1256 (2013)

40. N. Faber, Doctoral Thesis ERIM, Structuring warehouse management, 336, 1-153 (2015)

41. H., Hämäläinen, E., Salmela, A., Happonen, ISL 2007, RFID on Item Level Tagging in Supply Chain with High-Valued Products, pp. 390-395 (2007)

42. A., Happonen, H., Hämäläinen, J., Ikonen, SOFTCOM 2008, Radio identification in construction industry case: tagging hollow steel beams, p. 5 (2008)

43. Fuji Xerox Co., Reading an eight-page document. Case 1: Comparison of CO2 Emissions from an Environmental Perspective, https://www.fujixerox.com/eng/company/technolog $\mathrm{y} /$ production/ma/electronic_media/case1.html (2019)

44. I.A. Shah, S. Amjed, N.A. Alkathiri, The economics of paper consumption in offices, JOEBM, 20, 1, 4362 (2019)

45. J. Laverty, IRMS WM Blog, $86 \%$ of Businesses Will Be Digital in 5 Years: Are You Ready?, https://www.irms360.com/blog_post/86 businesses will be digital 5 years are you ready, (2015)

46. K.-S. Tan, M. D. Ahmed, D. Sundaram, EOMAS 2009, Sustainable warehouse management (2009)

47. H. Manner, Hub logistics, Hakkila Automated, https://www.hub.fi/wp- 
content/uploads/2018/11/Hakkila-AutomatedWarehouse-Service.pdf, (2018)

48. Finnair Cargo, 7 Of The Most Modern Air Cargo Terminals In The World, https://cargo.finnair.com/en/cargo-news/best-aircargo-terminals (2018)

49. Finnair Cargo, Cool Nordic Cargo Hub, https://cargo.finnair.com/en/cool (2019)

50. Finnair Cargo. Amazing Facts About Europe's Most Modern Air Cargo Terminal, Finnair's Cool Hub In Helsinki, (2019)

51. Finnair Cargo, Swissport Appointed New Terminal Operator At The Cool Nordic Cargo Hub In Helsinki. (2019)

52. J. Bond, $\mathrm{MMH}$, Cold storage: Planning for unpredictability., 68, 6, 24-28 (2013)

53. Finnair Cargo, Norwegian Seafood And Finnair Cargo: A Match Made In The Nordics, https://cargo.finnair.com/en/cargo-news/norwegianseafood-salmon-stories (2018)

54. Pharma Technology Focus, Finnair cargo: company insights,

https://pharma.nridigital.com/pharma apr19/finnair cargo company insight (2019)

55. Air Cargo News. Finnair opens 'cool' new Helsinki hub, https://www.aircargonews.net/airlines/finnairopens-cool-new-helsinki-hub/ (2017)

56. Finnair Cargo, What Does Green Air Cargo Terminal Design Look Like?, Available https://cargo.finnair.com/en/cargo-news/green-aircargo-terminal (2017)

57. J., Porras, A., Knutas, J., Ikonen, A., Happonen, J., Khakurel, A., Herala, 52nd HICSS, Code camps and hackathons in education - literature review and lessons learned, p. $7750-7759$ (2019)
58. J., Porras, J., Khakurel, J., Ikonen, A., Happonen, A. Knutas, A., Herala, O., Drögehorn, ICSE 2018, Hackathons in software engineering education lessons learned from a decade of events, p. 40-47 (2018)

59. A., Happonen, D., Minashkina, A., Nolte, M.A., Medina Angarita, Eureca 2019, Hackathons as a Company - University Collaboration Tool to Boost Circularity Innovations and Digitalization Enhanced Sustainability, p. 11 (2019)

60. S-K., Kinnunen, A., Happonen, S., Marttonen-Arola, T., Kärri, IJSEAM, Traditional and extended fleets in literature and practice: Definition and untapped potential, p. 20 (2019)

61. H., Kortelainen, A., Happonen, From data to decisions - the re-distribution of roles in manufacturing ecosystems, Available https://vttblog.com/2017/12/20/from-data-todecisions-the-re-distribution-of-roles-inmanufacturing-ecosystems/ (2017)

62. H., Kortelainen, A., Happonen, J., Hanski, Lecture Notes in Mechanical Engineering, From asset provider to knowledge company - transformation in the digital era, ISSN: 2195-4356, p. 333-341 (2019)

63. M., Ghoreishi, A. Happonen, ICEPP 2019, New Promises AI Brings into Circular Economy Accelerated Product Design: Review on Supporting Literature, p. 11 (2019)

64. M. Airola, E. Salmela, A. Happonen, ECIE 2011, Formalising network development in manufacturing SMEs, pp. 42-50 (2011)

65. H., Kortelainen, A., Happonen, S-K., Kinnunen, Lecture Notes in Mechanical Engineering, Fleet Service Generation -Challenges in Corporate Asset Management, ISBN: 978-3-319-27062-3, pp. 373$380(2016)$ 